\title{
ACESSO À CULTURA COMO A FUNÇÃO SOCIAL DOS DIREITOS AUTORAIS
}

\author{
Alessandra de Andrade Barbosa Santos de Mesquital \\ Alessandra Biolcati Rodrigues ${ }^{2}$ \\ Evandro Afonso de Mesquita \\ José Luis Rodrigues ${ }^{4}$ \\ Recebido em 05/08/2021 \\ Aceito em 11/09/2021
}

\begin{abstract}
RESUMO
O presente trabalho encara a problemática da relevância do acesso à cultura como elemento decorrente da função social dos direitos autorais, suas relações e seus efeitos sobre os limites da proteção. Destaca-se a relevância e importância do direito de acesso à cultura por meio de uma análise e apresentadas as normas jurídicas e fatos sociais que regulam e informam tanto os direitos culturais, em particular o direito de acesso às obras protegidas pelas normas autorais. Ao final conclui-se pela existência de elementos sociais e instrumentos jurídicos para uma efetiva concretização do direito de acesso à cultura, e pela necessidade de uma mudança na forma como são concebidas, interpretadas e aplicadas as normas jurídicas em questão.
\end{abstract}

PALAVRAS-CHAVE: Acesso à Cultura. Direitos Autorais. Função Social. Lei dos Direitos Autorais-LDA.

\footnotetext{
${ }^{1}$ Mestranda em Função Social do Direito pela faculdade FADISP-Faculdade Autônoma de Direito, Bolsista CAPES- Coordenação de Aperfeiçoamento de Pessoal de Nível Superior. Pós-Graduanda em Compliance, LGPD e Prática Trabalhista pelo IEPREV. Especialista Lato Sensu em Direito e Processo do Trabalho pela Universidade Mackenzie, Formada em Direito, em 2008, pela FARO - Faculdade de Rondônia. Advogada Trabalhista desde 2012. Celular (11) 96180-1822 E-mail alessandraemesquitaadv@ gmail.com.

${ }^{2}$ Mestranda em Função Social do Direito pela Faculdade Autônoma de Direito - FADISP. Especialista em Direito Civil e Processual Civil pela Escola Paulista de Direito - EDP. Especializando em Direito, Processo e Planejamento Tributário pela Escola Paulista de Direito - EPD. Graduação em Direito pela Universidade da Cidade de São Paulo. Advogada atuante na área cível no Estado de São Paulo e Rio de Janeiro. Sócia-diretora da Rodrigues e Biolcati Sociedade de Advogados. Coautora do livro: Ensaios de autonomia universitária e ensino jurídico da Editora Sem Fronteiras. (ISBN 978-65-991440-2-8)

${ }^{3}$ Mestrando em Função Social do Direito pela faculdade FADISP-Faculdade Autônoma de Direito, Especialista Lato Sensu em Direito Público pela Universidade Federal de Rondônia - UNIR, Graduado em Direito, em 2008, pela Faculdade de Rondônia - FARO. Auditor-Fiscal do Trabalho. Celular (11) 98755-2925. E-mail evandroafonso@hotmail.com .

${ }^{4}$ Mestrando em Função Social do Direito pela Faculdade Autônoma de Direito - FADISP. Especialista em Direito Civil e Processual Civil pela Escola Paulista de Direito - EDP. Especializando em Direito, Processo e Planejamento Tributário pela Escola Paulista de Direito - EPD. Graduação em Direito pela Universidade da Cidade de São Paulo. Advogado atuante na área cível no Estado de São Paulo e Rio de Janeiro. Sócio-diretor da Rodrigues e Biolcati Sociedade de Advogados. Coautor do livro: Ensaios de autonomia universitária e ensino jurídico da Editora Sem Fronteiras. (ISBN 978-65-991440-2-8)
} 


\section{ACCESS TO CULTURE AS THE SOCIAL FUNCTION OF COPYRIGHT}

\section{ABSTRACT}

The present work considers the issue of the relevance of access to culture as the social function of copyright, its relations and its effects on the limits of protection. It highlights the relevance and importance of the right of access to culture through an analysis and presents the legal norms and social facts that regulate and inform both cultural rights, the right of access to works protected by copyright norms. In the end, it is concluded that there are social elements and legal instruments for an effective realization of the right of access to culture, and the need for a change in the way the legal rules in question are conceived, interpreted and applied.

Keywords: Access to Culture. Copyright. Social role. Copyright Law-LDA

\section{INTRODUÇÃO}

O direito autoral costuma ser contemplando sob o ponto de vista econômico, que se propõe a proteger cegamente o dono da produção cultural ou, pior ainda, aquele que detém o direito de comercializar a propriedade intelectual alheia. Entretanto, sob a égide da Constituição Federal de 1988, que coloca os interesses coletivos em um patamar superior, em detrimento do interesse individual das normas protetivas do Direito do Autor. Isso não implica no desprezo ao direito autoral, apenas que a proteção legal deve ter como destinatário a sociedade de forma geral, sendo o direito autoral limitado formal e materialmente pelos princípios da função social e do acesso à informação.

A Cultura deriva e repercute sobre todas as atividades humanas, enquanto o Direito é uma ciência social que valoriza, qualifica, atribui consequências a um comportamento. Não em função de critérios filosóficos, religiosos ou subjetivos, mas em função da utilidade social, além de requerer alterações, a normatizar as relações sociais, impedindo o aparecimento e escalonamento de potenciais conflitos, essencialmente para proteção da pessoa humana. $\mathrm{O}$ elemento cultural influencia todas as relações sociais, inclusive as jurídicas e, sendo assim, o Direito deve ser abarcado como um reflexo da cultura de grupos no espaço e no tempo em que se compõem.

As artes também refletem os anseios e visões de mundo de seus criadores, intérpretes, seus Autores. Seu entendimento busca principalmente localizá-las no contexto das demais expressões humanas, incorporá-las na textura de um universo simbólico particular, atribuindolhes um significado cultural. Os admissíveis sentidos das artes são socialmente edificados para 
tanto que sua produção como análise são condicionados ao conjunto de experiências culturais vivenciadas pelos artistas como também pelo público. As artes são, enfim, expressões artísticoculturais e sociais.

O fenômeno cultura é ele próprio intermediador das relações humanas, que passa a ser também compreendido como objeto do Direito. Isto é resultado da crescente necessidade dos povos de resguardar suas peculiaridades contra uma ameaça de padronização cultural. Esses contornos e efeitos sobre o ordenamento jurídico começam a ser abrangidos e os direitos autorais, particularmente, sofrem a influência da normatividade transformada pelos direitos culturais.

O presente trabalho encara os problemas relativos ao conteúdo dos direitos culturais e põe em destaque a função social do direito autoral e seus efeitos sobre os limites da proteção quanto ao direito de acesso à cultura.

\section{DIREITO AUTORAL}

O direito autoral remonta aos primórdios da história da humanidade, muito antes da primeira norma positivada, em 1710, na Inglaterra, as normas de direito natural já protegiam o direito de autor explorar com exclusividade suas obras. Na Grécia na Roma antigas, aquele que violasse o direito de um autor sofria séria sanção moral, era tido como indigno de honra perante a sociedade.

Como será visto no capítulo seguinte, o conceito legal e doutrinário de direitos autorais adotados no Brasil está em perfeita harmonia com os conceitos adotados internacionalmente. Os direitos autorais recaem sobre qualquer criação artística, científica ou literária exteriorizada por qualquer meio.

Os direitos autorais são divididos em Direitos Morais e Direitos Patrimoniais, nas palavras de Fernanda Magalhães Marcial:

\footnotetext{
A doutrina jurídica clássica coube por dividi-los em Direitos Morais, que são os de natureza pessoal - personalíssimos, inalienáveis, onde se inserem os direitos de paternidade e integridade da Obra, pertencendo exclusivamente ao Autor que detêm os direitos de reivindicar, modificar, assegurar sua integridade e objetar quaisquer modificações ou prática de atos que possam prejudicá-la de qualquer forma, em sua reputação ou honra e a qualquer tempo, não podendo ser passíveis de cessão ou de renúncia pelo autor - e os Direitos Patrimoniais, que são os de natureza patrimonial aqueles que podem ser dispostos aos herdeiros, agentes etc., como os de utilizar, fruir, dispor da obra sob qualquer forma, enfim, os direitos de controle sobre a reprodução
} 
(na totalidade ou em parte), a edição, a tradução ou adaptação, a incorporação da obra em um fonograma ou numa obra audiovisual, dentre outros ${ }^{5}$.

Segundo José Ascensão o direito de autor é assim definido:

Direito de Autor é o ramo da ordem jurídica que disciplina a atribuição de direitos relativos a obras literárias e artísticas.

O Direito Autoral abrange além disso os chamados direitos conexos do direito do autor, como os direitos dos artistas intérpretes ou executantes, dos produtores de fonogramas e dos organismos de radiodifusão ${ }^{6}$

E ainda discorre sobre esse direito:

Direito Autoral passou, pois, ser designação de gênero. Trata-se de curiosa evolução, pois "direito autoral" é um neologismo, que foi introduzido por Tobias Barreto para corresponder à palavra alemã Urheberrechte - ou seja, justamente direito de autor. ${ }^{7}$

Nas palavras de Ascensão sobre O Direito Industrial (Propriedade Industrial)

Há um ramo, paralelo ao Direito de Autor, que deveremos referir mais de uma vez: é a propriedade Industrial. A sua proximidade é tanta que frequentemente se unificam Direito de Autor e Propriedade Industrial sob a designação de "Propriedade Intelectual". A organização internacional especializada nesta matéria chama-se mesmo Organização Mundial da Propriedade Intelectual (O.M.P.I) ${ }^{8}$

Toda obra intelectual, como música, arte, literatura, o seu autor, ou seja, o seu criador tem sobre a sua criação os cognominados "direitos autorais", podendo exercê-lo contra terceiros e contra a coletividade ou simplesmente não o exercer, pelo menos em princípio.

À princípio, detém o autor o direito exclusivo de monopólio da exploração econômica de sua obra. Esse monopólio visa remunerar a criação, estimulando novas produções artísticas e culturais. Decorridos os prazos estabelecidos em lei, a obra cai em domínio público, não remunerando mais o autor pela publicação ou exposição de seus trabalhos. No Brasil esse prazo, atualmente é de 70 anos.

\section{PROTEÇÃO DO DIREITO AUTORAL}

\footnotetext{
${ }^{5}$ MARCIAL, Fernanda Magalhães. Os Direitos Autorais, sua proteção, a liberalidade na internet e o combate à pirataria. Âmbito Jurídico. Publicado em 01/04/2010. Disponível: https://ambitojuridico.com.br/edicoes/revista-75/os-direitos-autorais-sua-protecao-a-liberalidade-na-internet-e-ocombate-a-pirataria/ Acessado em 28/06/2021.

${ }^{6}$ ASCENSÃO, José de Oliveira. Direito Autoral. $2^{\text {a }}$ Ed. Rio de Janeiro, Renovar. 1997. p. 15

${ }^{7}$ ASCENSÃO, José de Oliveira. Direito Autoral. $2^{\text {a }}$ Ed. Rio de Janeiro, Renovar. 1997. p. 16

${ }^{8}$ ASCENSÃO, José de Oliveira. Direito Autoral. 2. Ed. Rio de Janeiro: Renovar, 1997. P.20
} 
A preocupação em se proteger os direitos do autor tem origem recente e teria surgido, primeiramente, na Inglaterra. $\mathrm{Na}$ antiguidade a produção do conhecimento, principalmente o escrito, se dava de maneira artesanal pelos chamados monges copistas ${ }^{9}$ e, por isso mesmo, facilmente controlável. Com o surgimento da prensa mecânica e a possível democratização da informação, começou a haver a preocupação em se criar mecanismos de controle das obras.

A primeira referência a uma norma no Brasil protetiva dos direitos do autor surge na Constituição Imperial de $1824^{10}$, em seu artigo 179, XXVI: XXVI. Os inventores terão a propriedade das suas descobertas, ou das suas produções. A Lei lhes assegurará um privilégio exclusivo temporário, ou lhes remunerará em ressarcimento da perda, que hajam de sofrer pela vulgarização.

A Lei 5988/1973 ${ }^{11}$, que versava sobre Direitos Autorais foi revogada pela Lei 9610/1998 ${ }^{12}$, exceto o artigo 17 . O artigo 17 tratava do registro das obras intelectuais, e, notase, que não havia mais a exigência do registro da obra na Biblioteca Nacional como formalidade constitutiva, mas que este era recomendado para efeitos de segurança dos direitos. $\mathrm{O}$ registro passou, então, a poder ser feito em diversos órgãos, dependendo da natureza da obra, como segue, in verbis:

\begin{abstract}
Art. 17. Para segurança de seus direitos, o autor da obra intelectual poderá registrá-la, conforme sua natureza, na Biblioteca Nacional, na Escola de Música, na Escola de Belas Artes da Universidade Federal do Rio de Janeiro, no Instituto Nacional do Cinema, ou no Conselho Federal de Engenharia, Arquitetura e Agronomia. $§ 1^{\circ} \mathrm{Se}$ a obra for de natureza que comporte registro em mais de um desses órgãos, deverá ser registrada naquele com que tiver maior afinidade. $\$ 2^{\circ}$ O Poder Executivo, mediante Decreto, poderá, a qualquer tempo, reorganizar os serviços de registro, conferindo a outros Órgãos as atribuições a que se refere este artigo.
\end{abstract}

Com a promulgação da Constituição Federal em 1988 a tutela dos direitos autorais vem consignada no Título II - Dos Direitos e Garantias Fundamentais, Capítulo I, Dos Direitos e Deveres Individuais e Coletivos, no artigo $5^{\circ}$ caput, e incisos XXVII e XXVIII, que se faz necessário destacar:

\footnotetext{
${ }^{9}$ GEERTZ, Clifford. From the Native's Point of View: On the Nature of Anthropological Understanding. Bulletin of the American Academy of Arts and Sciences, vol. 28, n 1, out. 1974.

${ }^{10}$ BRASIL. Constituição Política do Império do Brasil, elaborada por um Conselho de Estado e outorgada pelo Imperador D. Pedro I. Disponível em: http://www.planalto.gov.br/ccivil_03/constituicao/constituicao24.htm. Acessado em: 28/06/2021

${ }^{11}$ BRASIL. Lei $\mathbf{n}^{\circ}$ 5.988, 14 de dezembro de 1973. Regula os direitos autorais e dá outras providências.

Disponível em: http://www.planalto.gov.br/ccivil_03/leis/L5988.htm. Acessado em 28/06/2021.

${ }^{12}$ BRASIL. Lei $\mathbf{n}^{\mathbf{0}}$ 9.610, de 19 de fevereiro de 1998. Altera, atualiza e consolida a legislação sobre direitos autorais e dá outras providências. Disponível em: http://www.planalto.gov.br/ccivil_03/leis/L9610.htm Acessado em 28/06/2021.
} 
Art. $5^{\circ}$ Todos são iguais perante a lei, sem distinção de qualquer natureza, garantindose aos brasileiros e aos estrangeiros residentes no País a inviolabilidade do direito à vida, à liberdade, à igualdade, à segurança e à propriedade, nos termos seguintes: (...) Omissis

XXVII - aos autores pertence o direito exclusivo de utilização, publicação ou reprodução de suas obras, transmissível aos herdeiros pelo tempo que a lei fixar; XXVIII - são assegurados, nos termos da lei: a) a proteção às participações individuais em obras coletivas e à reprodução da imagem e voz humanas, inclusive nas atividades desportivas; b) o direito de fiscalização do aproveitamento econômico das obras que criarem ou de que participarem aos criadores, aos intérpretes e às respectivas representações sindicais e associativas; (...) Omissis ${ }^{13}$

Não são objeto de proteção segundo a lei de direitos autorais, Lei n. 9610 de 19/02/1998 ${ }^{14}$, ideias, procedimentos normativos, sistemas, métodos, projetos ou conceitos matemáticos como tais; esquemas, planos ou regras para realizar atos mentais, jogos ou negócios; aproveitamento industrial ou comercial das ideias contidas nas obras

Além da proteção constitucional a lei em vigor que tutela os direitos autorais, como já mencionado anteriormente, a Lei 9610 de 19/02/1998 ${ }^{15}$, conhecida pela sua abreviação - LDA, que teve por seus objetivos alterar, atualizar e consolidar a legislação sobre os direitos autorais, ainda entendidos sob essa denominação como os direitos do autor e os que lhe sejam associados, conforme preceitua em seu artigo $1^{\circ}$. Também dispõe, em seu artigo $3^{\circ}$, que os direitos autorais são direitos, para fins legais, que devem ser considerados como bens móveis. $\mathrm{O}$ artigo $7^{\circ}$ da LDA ${ }^{16}$ traz a definição do que sejam as obras protegidas: "São obras intelectuais protegidas as criações do espíritos, expressas por qualquer meio ou fixadas em qualquer suporte, tangível ou intangível, conhecido ou que se invente no futuro (...)" e as lista. A Lei ainda define no artigo 11, o autor como a pessoa criadora de obra literária, artística ou científica; podendo o reconhecimento ser estendido às pessoas jurídicas, nos casos previstos. Em seu artigo 18 a Lei traz a definido que a proteção aos direitos autorais independe do registro da obra.

Para Eliane Y. Abrão

A Proteção aos direitos de autor tem um propósito: o de reservar por meio de um privilégio temporário e exclusivo aos artistas, escritores, compositores, desenhistas, pintores, escultores e outros criadores de obras de cunho estético, intelectual, cultural, um direito de ordem econômica, e outro de índole moral, para que sejam estimulados

\footnotetext{
${ }^{13}$ Ibidem p.4.

${ }^{14}$ BRASIL. Lei $\mathbf{n}^{\mathbf{0}}$ 9.610, de 19 de fevereiro de 1998. Altera, atualiza e consolida a legislação sobre direitos autorais e dá outras providências. Disponível em: http://www.planalto.gov.br/ccivil_03/leis/L9610.htm Acessado em 28/06/2021.

15 Ibidem p.4

${ }^{16}$ Ibidem p.4
} 
a produzirem sempre, e cada vez mais, garantindo-lhes o respeito à obra e a uma forme de sobrevivência condigna ${ }^{17}$.

No artigo 46 da Lei de Direitos Autorais, sob o n ${ }^{\circ} 9.610$ de 19/02/1998 ${ }^{18}$, segundo Eliane Y. Abrão:

(...) encontram-se situações de exceção a direitos e obras originariamente protegidos, e que só tem o seu uso liberado, por expressa isenção legal, tendo em vista situações excepcionais, nas quais o interesse público, a disseminação do conhecimento, ou mesmo o interesse mútuo de produtores e titulares na comercialização da obra avulta sobre o direito individual do autor. ${ }^{19}$

Quando trata dos direitos morais a $\mathrm{LDA}^{20}$ diz ser possível que o autor pode reivindicar a autoria, ter seu nome na obra, mantê-la inédita e assegurar a sua integridade, esses direitos são transmissíveis aos herdeiros por ocasião da morte do autor. Dispõe, ainda, que compete ao Estado a proteção à integridade e à autoria da obra caída no domínio público e que os direitos morais do autor são inalienáveis e irrenunciáveis.

Nesse diapasão José Ascensão discorre com o seguinte questionamento:

\footnotetext{
Será possível apresentar princípios que justificam uma autonomização do Direito Penal ou do Direito de Trabalho.

Acontecerá assim com o Direito do Autor? É evidente a índole ou fisionomia específica deste setor, a que está ligada uma grande complexidade. Mas já não é evidente a existência de princípios próprios, porque a doutrina não tem tido a preocupação de demarcá-los. ${ }^{21}$
}

Para a proteção aos direitos autorais temos outras leis e convenções que os protegem, das quais elencamos alguns:

$\checkmark$ Lei $n^{\circ} .9 .615$ de 24 de março de 1998 - Institui normas gerais sobre o desporto, tratando do direito de arena, sendo denominada como 'Lei Pelé'22;

$\checkmark$ Lei $n^{\circ} .9 .472$ de 16 de julho de 1997 - Dispõe sobre a organização dos serviços de telecomunicações, a criação e funcionamento de um órgão regulador e outros

\footnotetext{
${ }^{17}$ ABRÃO, Eliane y. Direitos do Autor e Direitos Conexos.2014. p. 337

18 Ibidem p.4

${ }^{19}$ ABRÃO, Eliane y. Direitos do Autor e Direitos Conexos.2014. p. 342

${ }^{20}$ Ibidem $\mathrm{p} .4$

${ }^{21}$ ASCENSÃO, José de Oliveira. Direito Autoral. $2^{\text {a }}$ Ed. Rio de Janeiro, Renovar. 1997. p. 18

${ }^{22}$ BRASIL. Lei no 9.615 de 24 de março de 1998 - Institui normas gerais sobre o desporto, tratando do direito de arena, sendo denominada como 'Lei Pelé'. Disponível em:

http://www.planalto.gov.br/ccivil_03/leis/19615consol.htm Acessado em: 28/06/2021.
} 
aspectos institucionais, nos termos da Emenda Constitucional 8 de 1995, sendo conhecida como 'Lei Geral de Telecomunicações'²3;

$\checkmark$ Lei $n^{\circ}$. 6.533, de 24 de maio de 1978 - Dispõe sobre a regulamentação das profissões de artista e de técnico em espetáculos de diversões, e dá outras providências; ${ }^{24}$

$\checkmark$ Convenção de Genebra - Decreto nº 76.906, de 24 de dezembro de 1975. Convenção de Genebra para a proteção de produtores de fonogramas contra reproduções não autorizadas; $;^{25}$

$\checkmark$ Decreto $n^{\circ} .75 .541$ de 31 de março de 1975 - Promulga a Convenção que instituiu a Organização Mundial da Propriedade Intelectual - OMPI; ${ }^{26}$

$\checkmark$ Decreto $\mathrm{n}^{\circ} .76 .906$, de 24 de dezembro de 1975 - Promulga a Convenção para a proteção de produtores de fonogramas contra a reprodução não autorizada de seus fonogramas, concluída em Genebra, em 29.10.1971;27

$\checkmark$ Decreto $n^{\circ} .57 .125$, de 19 de outubro de 1965 - Promulga a Convenção Internacional para proteção aos artistas intérpretes ou executantes, aos produtores de fonogramas e aos organismos de radiodifusão, assinada em Roma, em 26.10.1961;28

Decreto-Lei $\mathrm{n}^{\circ} .980$, de 20 de outubro de 1969 - Dispõe sobre a cobrança de direitos autorais nas exibições cinematográficas ${ }^{29}$;

\footnotetext{
${ }^{23}$ BRASIL. Lei no 9.472 de 16 de julho de 1997 - Dispõe sobre a organização dos serviços de telecomunicações, a criação e funcionamento de um órgão regulador e outros aspectos institucionais, nos termos da Emenda Constitucional 8 de 1995, sendo conhecida como 'Lei Geral de Telecomunicações'. Disponível em: http://www.planalto.gov.br/ccivil_03/leis/19472.htm Acessado em: 28/06/2021.

${ }^{24}$ BRASIL. Lei no 6.533, de 24 de maio de 1978 - Dispõe sobre a regulamentação das profissões de artista e de técnico em espetáculos de diversões, e dá outras providências. Disponível em: http://www.planalto.gov.br/ccivil_03/leis/16533.htm Acessado em: 28/06/2021.

${ }^{25}$ BRASIL. Decreto $\mathbf{n}^{\mathbf{0}} \mathbf{7 6 . 9 0 6}$, de 24 de dezembro de 1975 - Promulga a Convenção para a proteção de produtores de fonogramas contra a reprodução não autorizada de seus fonogramas, concluída em Genebra, em 29.10.1971. Disponível em: https://www2.camara.leg.br/legin/fed/decret/1970-1979/decreto76906-24-dezembro-1975-425566-publicacaooriginal-1-pe.html Acessado em: 28/06/2021.

${ }^{26}$ BRASIL. Decreto no 75.541 de 31 de março de 1975 - Promulga a Convenção que instituiu a Organização Mundial da Propriedade Intelectual - OMPI. Disponível em: https://www2.camara.leg.br/legin/fed/decret/1970-1979/decreto-75541-31-marco-1975-424175publicacaooriginal-1-pe.html Acessado em 28/06/2021.

${ }^{27}$ BRASIL. Decreto no 76.906, de 24 de dezembro de 1975. Convenção de Genebra para a proteção de produtores de fonogramas contra reproduções não autorizadas. Disponível em: https://www2.camara.leg.br/legin/fed/decret/1970-1979/decreto-76906-24-dezembro-1975-425566publicacaooriginal-1-pe.html Acessado em: 28/06/2021.

${ }^{28}$ BRASIL. Decreto n ${ }^{\mathbf{0}}$ 57.125, de 19 de outubro de 1965 - Promulga a Convenção Internacional para proteção aos artistas intérpretes ou executantes, aos produtores de fonogramas e aos organismos de radiodifusão, assinada em Roma, em 26.10.1961. Disponível em:

https://www2.camara.leg.br/legin/fed/decret/1960-1969/decreto-57125-19-outubro-1965-397457-

publicacaooriginal-1-pe.html Acessado em: 28/06/2021.

${ }^{29}$ BRASIL. Decreto-Lei $\mathbf{n}^{\mathbf{0}}$ 980, de 20 de outubro de 1969 - Dispõe sobre a cobrança de direitos autorais nas exibições cinematográficas. Disponível em: https://www2.camara.leg.br/legin/fed/declei/19601969/decreto-lei-980-20-outubro-1969-376304-publicacaooriginal-1-pe.html Acessado em: 28/06/2021.
}

Ponto de Vista Jurídico | Caçador | v.10 | nº 2 | p. 80 - 99 |jul./dez. 2021 
Lei $n^{\circ} .2 .415$, de 9 de fevereiro de 1955 - Dispõe sobre a outorga da licença autoral no rádio e televisão ${ }^{30}$;

Nesse contexto da proteção dos Direitos do Autor temos a velha e famigerada pirataria, atualmente definida como pirataria moderna, pois é sintetizada pela prática de reproduzir, distribuir, ou mesmo vender produtos sem autorização dos proprietários de um produto ou de uma marca ${ }^{31}$. De acordo com a legislação vigente no país no artigo 184 do Código Penal ${ }^{32}$, a pirataria é crime, e a pena pode chegar a quatro anos de reclusão e multa, para isso se faz necessária uma consolidação e estruturação das normas que protegem os direito do autor, de forma a reforçar os mecanismos de controle e fiscalização.

\section{FUNÇÃO SOCIAL DO DIREITO AUTORAL}

Segundo Cristiano Chaves e Nelson Rosenvald ${ }^{33}$, o direito romano, ainda que tenha um legado de propriedade irrestrita, despontava uma submissão do exercício da propriedade ao interesse social, a qual resta em proeminência a prerrogativa do princípio da humanidade sobre os outros princípios do direito "o que permite que se afaste também o individualismo como característica da propriedade romana, pois mesmo quando exercida individualmente, a propriedade romana sempre esteve sujeita ao interesse social.".

Para Norberto Bobbio ${ }^{34}$ a função social é enfrentada "pelo viés da passagem do direito repressivo para o direito promocional". O direito repressivo buscava reprovar todo aquele que praticasse uma conduta oposta aos interesses coletivos, o Estado promocional para Bobbio, pretende incentivar todas as condutas que sejam coletivamente úteis, mediante a imposição de sanções positivas, capazes de estimular uma atividade, uma obrigação de fazer.

Como o direito autoral vem expressamente garantido pela Constituição de 1988, imperativa a interpretação de que, como sendo também direito de propriedade, se submete à interpretação sistemática de necessário cumprimento da função social também por esse instituto

\footnotetext{
${ }^{30}$ BRASIL. Lei $\mathbf{n}^{\mathbf{2}} \mathbf{2 . 4 1 5}$, de 9 de fevereiro de 1955 - Dispõe sobre a outorga da licença autoral no rádio e televisão. Disponível em: http://www.planalto.gov.br/ccivil_03/LEIS/1950-1969/L2415.htm Acessado em 28/06/2021.

${ }^{31}$ DANTAS, Tiago. "Pirataria"; Brasil Escola. Disponível em:

https://brasilescola.uol.com.br/curiosidades/pirataria.htm. Acesso em 28 de junho de 2021.

${ }^{32}$ BRASIL. Decreto-Lei no 2.848, de 7 de dezembro de 1940. Código Penal. Disponível em: http://www.planalto.gov.br/ccivil_03/decreto-lei/del2848compilado.htm Acessado em: 28/06/2021.

${ }^{33}$ ROSENVALD, Nelson; FARIAS, Cristiano Chaves de. Direitos Reais. Rio de janeiro: Lumen Juris, 2007.

${ }^{34}$ BOBBIO, Norberto. Da estrutura à função: novos estudos da teoria do direito. São Paulo: Manole, 2007.
} 
que apresenta o rol dos direitos e garantias fundamentais -, mais precisamente em seu Capítulo I, dedicado aos direitos e deveres individuais e coletivos.

Quando se fala em produção intelectual, ou criação do espírito humano, deve se remeter sobre o que, exatamente, vem a ser tutelado pela esfera jurídica. Para Ascensão ${ }^{35}$ as ideias, uma vez concebidas, são patrimônio comum da humanidade e que seria inconcebível um sistema que pretendesse restringir a utilização delas.

Com isso depreende-se que a garantia aos direitos autorais nasce quando a criação é exteriorizada. No mesmo sentido Staut Júnior ${ }^{36}$ afirma que o discurso tradicional relativo aos direitos autorais deixa claro o que é considerado e protegido como — produção intelectual: —a criação não se confunde com a ideia, que pode, e que em um contexto de indústria cultural deve ser idêntica ao que já se produziu em determinada área. Para o autor toda a tutela se fundamenta no que deve ser entendido por criação, assim sendo:

(...) Isso significa dizer que não se protege o pensamento e sim a sua materialização, que deve possuir um mínimo de criatividade ou originalidade estética. É isto que significa a — criação, conceito que fundamenta a tutela da atividade autoral, para o discurso tradicional dos direitos autorais.

A Para Isabel Vaz a incidência do princípio da função social sobre os direitos autorais, cabível o que a seguir se destaca:

O progresso cultural e o avanço tecnológico multiplicaram as modalidades de criação do espírito humano, entendidas atualmente como necessárias à satisfação de um interesse social, que, a despeito da proteção dos direitos autorais, sobrepõe-se ao interesse do indivíduo-autor.

Encontram-se, assim, em presença, dois tipos de interesses 'igualmente legítimos e igualmente inafastáveis', competindo ao Estado atender 'de maneira igualmente satisfatória a ambos: de um lado, o autor, cujo trabalho pessoal e criativo (dando uma forma especial às ideias) deve ser protegido e recompensado e, de outro, a sociedade que lhe fornece a matéria prima dessa obra, constituindo seu receptáculo natural. ${ }^{37}$

Primeiramente temos que entender ou esclarecer que tudo aquilo que existe desempenha à uma determinada função, ainda que alguma coisa possa ser destinada à mais de uma finalidade, há que se destacar uma finalidade precípua. Quando percebemos que enquanto um determinado bem alcança suas finalidades, principais ou secundárias, ele atende a necessária função social.

\footnotetext{
${ }^{35}$ ASCENSÃO, José de Oliveira. Direito Autoral. $2^{\text {a }}$ Ed. Rio de Janeiro, Renovar. 1997.

36 STAUT JÚNIOR, S.S. Direitos Autorais entre as relações sociais e as relações jurídicas. Curitiba: Moinho do Verbo, 2006.

${ }^{37}$ VAZ, Isabel. Direito econômico das propriedades. $1^{a}$ ed. Rio de Janeiro: Forense, 1992
}

Ponto de Vista Jurídico | Caçador | v.10|nº 2 | p. 80 - 99 | jul./dez. 2021 


\section{DIREITO DE ACESSO À CULTURA}

Clifford Geertz, no pensamento de Max Weber, ao delinear o homem como um animal suspenso em teias de significância construídas por eles mesmos, e assumir que cultura é o conjunto destas teias, indica que sua análise não deve ser de uma ciência experimental em busca de leis gerais, mas uma interpretativa na procura de sentidos para a vida ${ }^{38}$. Nesse diapasão, o autor prossegue com a conceituação do fenômeno cultural estampando uma característica conceitual, em que cultura é a estrutura dos sentidos, ideias e significados que uma determinada visão de mundo contém ${ }^{39}$, e a o que se almeja a quem estuda o tema é revelar esta estrutura simbólica e, para tal, deve, por meio do processo hermenêutico, equivalente à história, literatura, filosofia, buscar interpretativamente erguer as formas de pensamento e expressão dos membros daquele grupo ou comunidade. ${ }^{40}$

Os direitos autorais garantem proteção à obra, por outro lado, o acesso à cultura nasce disso, nasce do encontro de interesses entre o autor e a sociedade. Atualmente, pelo crescimento da internet e mais pessoas tendo acesso aos mais variados tipos de material, várias são as formas de acesso à produção intelectual, e esses meios nem sempre são facilmente controláveis, ou quase impossível por assim dizer. A doutrina demonstra numa crença da existência de uma indústria cultural, que encara as obras como objetos, e que tenta até mesmo manter controle da criatividade do artista, para que esta se ajuste ao mercado, onde as produções seriam guiadas pelo consumo que a sociedade escolher.

Para Losso ${ }^{41}$, ao examinar a história dos discursos jurídicos sobre os direitos autorais se revelam os sentidos e os fundamentos desses direitos, criados e moldados para atender, abrigar, mas também produzir poderes que estão presentes nas relações sociais e que não são facilmente identificados nas relações jurídicas abstratas, embora possam ser produzidos, inclusive, por elas. Nesse espaço dominado pela indústria cultural isso não é nem um pouco diferente. Só tem sentido valorizar uma criação apenas ou principalmente pela envergadura econômica, assim como inventar todo um conjunto de ferramentas jurídicas que possibilitam o trânsito econômico desses bens culturais, em uma determinada sociedade.

\footnotetext{
${ }^{38}$ GEERTZ, C. A Interpretação das Culturas. Rio de Janeiro: Guanabara, 1989. p.5.

${ }^{39}$ SHWEDER, Richard A. Preview: a colloquy of culture theorists. In: SHWEDER, Richard A. LEVINE, Robert. Culture theory: essays on mind, self and emotion. New York: Cambridge University Press, 1984.p.8 ${ }^{40}$ GEERTZ, C. From the Native's Point of View: on the nature of anthropological understanding. In: Local Knowledge Further Essays in Interpretative Anthrpology, New York: Basic Books, 1983.

${ }^{41}$ LOSSO, F.M. Os direitos autorais no Mercado da música. 253 f. Tese (Doutorado em Direito) - Faculdade de Direito, Universidade de São Paulo, São Paulo, 2008.
} 
Como um criador poderia ou teria o direito de resistência sobre as normas que por certo são apropriadas para atender a função social que nasce junto com sua obra, para Tomas Hobbes define o direito natural de resistência como um espectro do direito de liberdade da seguinte forma: “(...) a verdadeira liberdade dos súditos, ou seja, quais são as coisas que, embora ordenadas pelo soberano, não obstante eles podem sem injustiça recusar-se a fazer"42.

O mandamento constitucional constante do art. $5^{\circ}$, inciso XXIII, da Lei Maior, dispõe que a propriedade deverá atender a sua função social, a determinação alcança a propriedade de bens imóveis e móveis. Sendo o Direito Autoral a propriedade de um bem móvel, essa atinge sua função social quando assegura o direito de acesso à cultura para todos os cidadãos, independente de posses e renda, pois este é uma forma de função social do bem.

Nesse sentido Eliane Y. Abrão nos aclara sobre a saudável repartição dos direitos autorais:

A Razão é a mesma, tanto no direito autoral, quanto na propriedade industrial: devolver à sociedade o uso e o gozo do privilégio concedido ao autor/inventor que dela retirou elementos para compor sua obra, ou seu invento, em uma saudável repartição de direitos. ${ }^{43}$

Com relação aos direitos patrimoniais, a Lei de Direitos Autorais ${ }^{44}$ determina que cabe exclusivamente ao autor o direito de utilizar, fruir e dispor da obra literária, artística ou científica, e que a utilização por terceiros, nas mais diversas modalidades, depende de expressa autorização prévia.

As disposições legais abrem a possibilidade de utilização de uma obra, ainda que protegida, onde uma de suas dimensões perde força: a dimensão patrimonial. Pimenta ${ }^{45}$ clarifica:

O aproveitamento fixado na legislação, com as limitações demonstram o interesse social, que, fundado na liberdade de aproveitamento para a coletividade, na igualdade para todos de aproveitamento e visando ao desenvolvimento tecnológico e o progresso cultural delineia o princípio cursionador do equilíbrio entre o direito do titular e o interesse coletivo. As limitações, ora versadas, referem-se ao uso da obra intelectual em que não se necessita de autorização e, por conseguinte, são isentas do pagamento de royalties aos titulares de direitos autorais - nascendo o princípio da livre utilização.

\footnotetext{
${ }^{42}$ HOBBES, Tomas. Leviatã ou matéria, forma e poder de um estado eclesiástico e civil. Tradução de João Paulo Monteiro e Maria Beatriz Nizza da Silva. São Paulo: Editora Nova Cultural, 1997 (Coleção Pensadores). capítulo XXI do Leviatã, XXI, p. 175.

${ }^{43}$ ABRÃO, Eliane y. Direitos do Autor e Direitos Conexos.2014. p. 338

${ }^{44}$ Ibidem p.5

${ }^{45}$ PIMENTA, E.S. A função social dos direitos autorais da obra audiovisual. $156 \mathrm{f}$. Tese (Doutorado em Direito) - Departamento de Direito Civil, Universidade de São Paulo, São Paulo, 2008. P. 67.
} 
A Convenção de BERNA ${ }^{46}$, proveniente de legislações pós Revolução Francesa, é sedimentada para a proteção da produção intelectual na sua dupla dimensão, os 28 direitos patrimoniais e os direitos morais. Associada com o copyright ${ }^{47}$, que busca primariamente a tutela do lado patrimonial, esses dois sistemas dominam as normatizações jurídicas com relação aos direitos autorais. Nessa Convenção de Berna que também, que se acham os conceitos e conjuntos jurídicos, que dão o substrato para o atual sistema de direitos autorais adotado no Brasil. O arcabouço, o fundamento, os objetivos e a função dos direitos autorais estão todos presentes nessa convenção internacional. Destarte, a Convenção de Berna aplica as duas dimensões dos direitos autorais, tanto a moral quanto a patrimonial. O Brasil, como signatário teria contraído essa dimensão moral por meio dessa Convenção, já que a Constituição Federal de $1988^{48}$ teria disposto de caráter expresso e evidente apenas sobre a dimensão patrimonial; gerando discussões doutrinárias sobre se o art. 24 da LDA $^{49}$ extrapolaria os limites constitucionais.

O Brasil, como signatário da Convenção de Berna, tem nesse sistema a base de suas leis autorais que, de acordo com Staut Junior ${ }^{50}$ confere ao direito do autor o patamar de direito natural do homem, como sendo os direitos autorais como de certo os direitos fundamentais que necessitam ser resguardados de forma tanto no seu aspecto público (liberdade de expressão) quanto no seu aspecto privado (um direito individual/privado do autor sobre a sua obra).

$\mathrm{O}$ direito de acesso à cultura tem igual importância, pois as diferentes formas de acesso condicionam inclusive o direito de produção cultural. $\mathrm{O}$ acesso à cultura é, assim sendo, a condição imperativa para a existência mesma do Direito de Autor e a concretização de quaisquer dos direitos relativos a produções culturais.

Portanto, "o papel do poder público deve ser de favorecer a livre procura das manifestações culturais, criar condições de acesso popular à cultura, prover meios para que a difusão cultural se fundamente nos critérios de igualdade" ${ }_{51}$. Deste modo, "a ação cultural do Estado há de ser ação afirmativa que busque realizar a igualização dos socialmente desiguais, para que todos, igualmente, aufiram os benefícios da cultura" ${ }^{52}$.

\footnotetext{
${ }^{46}$ BRASIL. Decreto no 75.699, de 6 de maio de 1975. Promulga a Convenção de Berna para a Proteção das Obras Literárias e Artísticas, de 9 de setembro de 1886, revista em Paris, a 24 de julho de 1971. Disponível em: http://www.planalto.gov.br/ccivil_03/decreto/1970-1979/D75699.htm Acessado em:28/06/2021.

${ }^{47}$ Direito Autoral

${ }^{48}$ Ibidem p.4

${ }^{49}$ Ibidem p.4

${ }^{50}$ STAUT JÚNIOR, S.S. Direitos Autorais entre as relações sociais e as relações jurídicas. Curitiba: Moinho do Verbo, 2006.

${ }^{51}$ SILVA, José Afonso da. Ordenação constitucional da cultura. São Paulo: Malheiros, 2001.p.48

${ }^{52}$ SILVA, José Afonso da. Ordenação constitucional da cultura. São Paulo: Malheiros, 2001.p.49
} 
Partindo dos dispositivos normativos vigentes é imperativo finalizar que tanto o direito de acesso à cultura quanto os direitos autorais estão de igual forma protegidos como direitos fundamentais. Se existir qualquer proeminência de um sobre o outro é no sentido de ser o direito de acesso preponderante sobre os direitos autorais. Não obstante, nos casos em que esses direitos constituídos caem sobre essas conjunturas e juntos delineiam uma confrontação, o tema é mais bem colocado no sentido de promover a conexão entre ambos e não a exclusão de algum deles. E como se expressa Ascensão $0^{53}$ em que o Direito de Autor é necessariamente o Direito à Cultura.

\section{CONSIDERAÇÕES FINAIS}

São causas da desigualdade e exclusões culturais as restrições à fruição dos bens culturais, no qual afeta a dignidade da pessoa humana quando se extrai do conceito dos princípios constitucionais, o exercício da cidadania e a democracia e, por estas implicações, o impedimento de acesso ofende os objetivos e fundamentos expostos em nossa Constituição. Destarte, qualquer restrição ao acesso tem de ser ao mesmo tempo corroborada, avaliando juntamente com outros direitos fundamentais, e, ao mesmo tempo, não causar nenhum dos desequilíbrios sociais quanto ao direito do Autor e o direito de acesso à cultura.

Como fundamentais que são, os direitos culturais, entre outras coisas, exigem ações positivas. As obrigações prestacionais são derivadas das normas constitucionais para que possa se impor obrigações ao Estado de legislar, construindo uma estrutura jurídica para o direito de acesso à cultura de forma a viabilizar um exercício positivo do direito à cultura. Uma imposição específica destes direitos também um dever específico, mormente ao Judiciário, de interpretar as normas jurídicas infraconstitucionais partindo do reconhecimento do direito a cultura como um direito fundamental.

Os Direitos Culturais se concretizam de uma demanda da existência de espaços culturais públicos e instrumentalizados para a conhecimento pleno e com liberdade para o exercício de uma vida cultural. A inclusão de uma implantação deriva da instrumentalização criando condições materiais e imateriais, dentre as quais a construção de espaços físicos e equipamentos técnicos que viabilizem as expressões e manifestações, o conhecimento e como se criar, fazer e noticiar e as condições jurídicas e econômicas que viabilize esta participação e exercício qualificados.

\footnotetext{
${ }^{53}$ ASCENSÃO, José de Oliveira. Direito Autoral. 2a Ed. Rio de Janeiro, Renovar. 1997.
} 
Os espaços culturais livres, onde as manifestações culturais são incondicionadas, são fonte de culturas, e sua minimização subtrai o dinamismo cultural e o sustento dessa cultura é retirado. O sustento das manifestações culturais livres são as próprias interações culturais livres, incondicionadas e espontâneas. Resguardar, proteger e ampliar deve ter como prioridade implantação ascendente dos direitos culturais no Brasil, com todas as suas nuances.

Para o um genuíno reconhecimento e concretização dos direitos culturais deve se lançar mão dos instrumentos jurídicos que estão à disposição dos operadores ou agentes do direito, independentemente de sua atuação nessa esfera jurídica, sejam eles advogados, defensores, promotores, procuradores, magistrados ou juristas.

Diante das adversidades que se apresentam para a efetivação do direito de acesso à cultura e aos direitos autorais as escolhas dos agentes não são estritamente fundadas na técnica jurídica, mas em opções políticas dos envolvidos. A seleção dos dispositivos e dos fatos sociais considerados relevantes, a análise dos efeitos de determinada posição ou decisão, as soluções encontradas e suas justificativas, são influenciados e condicionados pela visão de mundo e formação cultural dos agentes e são, portanto, culturalmente condicionadas. O pleno reconhecimento e concretização dos direitos culturais dependem, acima de tudo, de uma reformulação intelectual de alcance cultural do próprio campo jurídico.

E diante do contexto contemporâneo internacional, onde o diferencial está cada vez mais nos conteúdos simbólicos e culturais, nem os poderes constituídos nem a sociedade podem prescindir desta transformação. Para tal, será preciso uma mudança cultural no Direito que reconheça o valor, e se dê o devido valor, inclusive econômico, e importância dos direitos culturais e do direito de acesso à cultura.

Discute-se sobre a existência de dispositivos constitucionais conflitantes, direitos autorais versus direito de acesso à cultura, qual deve ser preterido? Deve haver um sopesamento entre ambos os princípios e a conclusão tem sido que o acesso à cultura a função social do direito autoral. Nesse sentido, compreende-se a necessidade de sobrepor o interesse público ao privado.

Pelo já exposto, se observa que o constituinte quis ser bem enfático quanto à limitação do direito de propriedade, caso não tenha função social, não terá amparo legal, então o titular do direito estará sujeito à perda do direito de propriedade caso outrem, ou mesmo o Estado, lhe atribua uma função social. A proteção ao Direito do Autor é ampla no direito brasileiro, mas não irrestrita, devendo o titular do direito exercê-lo de modo a garantir sua função social. 


\section{REFERÊNCIAS}

ABRÃO, Eliane y. Direitos do Autor e Direitos Conexos.2014.

ASCENSÃO, José de Oliveira. Direito Autoral. 2a Ed. Rio de Janeiro. Renovar. 1997.

BOBBIO, Norberto. Da estrutura à função: novos estudos da teoria do direito. São Paulo: Manole, 2007.

BRASIL. Constituição da República Federativa do Brasil. Disponível em: http://www.planalto.gov.br/ccivil_03/constituicao/constituicao.htm. Acessado em 28/06/2021.

BRASIL. Constituição Política do Império do Brasil, elaborada por um Conselho de Estado e outorgada pelo Imperador D. Pedro I. Disponível em: http://www.planalto.gov.br/ccivil_03/constituicao/constituicao24.htm . Acessado em 28/06/2021.

BRASIL. Decreto $n^{\circ}$ 57.125, de 19 de outubro de 1965 - Promulga a Convenção Internacional para proteção aos artistas intérpretes ou executantes, aos produtores de fonogramas e aos organismos de radiodifusão, assinada em Roma, em 26.10.1961. Disponível em: https://www2.camara.leg.br/legin/fed/decret/1960-1969/decreto-57125-19outubro-1965-397457-publicacaooriginal-1-pe.html Acessado em: 28/06/2021.

BRASIL. Decreto no 75.541 de 31 de março de 1975 - Promulga a Convenção que instituiu a Organização Mundial da Propriedade Intelectual - OMPI. Disponível em: https://www2.camara.leg.br/legin/fed/decret/1970-1979/decreto-75541-31-marco-1975424175-publicacaooriginal-1-pe.html Acessado em 28/06/2021.

BRASIL. Decreto no 75.699, de 6 de maio de 1975. Promulga a Convenção de Berna para a Proteção das Obras Literárias e Artísticas, de 9 de setembro de 1886, revista em Paris, a 24 de julho de 1971. Disponível em: http://www.planalto.gov.br/ccivil_03/decreto/19701979/D75699.htm Acessado em:28/06/2021.

BRASIL. Decreto no 76.906, de 24 de dezembro de 1975 - Promulga a Convenção para a proteção de produtores de fonogramas contra a reprodução não autorizada de seus fonogramas, concluída em Genebra, em 29.10.1971. Disponível em: https://www2.camara.leg.br/legin/fed/decret/1970-1979/decreto-76906-24-dezembro-1975425566-publicacaooriginal-1-pe.html Acessado em: 28/06/2021. 
BRASIL. Decreto $\mathbf{n}^{0}$ 76.906, de 24 de dezembro de 1975. Convenção de Genebra para a proteção de produtores de fonogramas contra reproduções não autorizadas. Disponível em: https://www2.camara.leg.br/legin/fed/decret/1970-1979/decreto-76906-24-dezembro1975-425566-publicacaooriginal-1-pe.html Acessado em: 28/06/2021.

BRASIL. Decreto-Lei no ${ }^{\circ .848, ~ d e ~} 7$ de dezembro de 1940. Código Penal. Disponível em: http://www.planalto.gov.br/ccivil_03/decreto-lei/del2848compilado.htm Acessado em: 28/06/2021.

BRASIL. Decreto-Lei $\mathbf{n}^{\circ}$ 980, de 20 de outubro de 1969 - Dispõe sobre a cobrança de direitos autorais nas exibições cinematográficas. Disponível em: https://www2.camara.leg.br/legin/fed/declei/1960-1969/decreto-lei-980-20-outubro-1969376304-publicacaooriginal-1-pe.html Acessado em: 28/06/2021.

BRASIL. Lei $\mathbf{n}^{\circ}$ 2.415, de 9 de fevereiro de 1955 - Dispõe sobre a outorga da licença autoral no rádio e televisão. Disponível em:

http://www.planalto.gov.br/ccivil_03/LEIS/1950-1969/L2415.htm. Acessado em 28/06/2021.

BRASIL. Lei $n^{0}$ 5.988, 14 de dezembro de 1973. Regula os direitos autorais e dá outras providências. Disponível em: http://www.planalto.gov.br/ccivil_03/leis/L5988.htm Acessado em 28/06/2021.

BRASIL. Lei $n^{0}$ 6.533, de 24 de maio de 1978 - Dispõe sobre a regulamentação das profissões de artista e de técnico em espetáculos de diversões, e dá outras providências. Disponível em: http://www.planalto.gov.br/ccivil_03/leis/16533.htm Acessado em: 28/06/2021.

BRASIL. Lei n⿳ 9.472 de 16 de julho de 1997 - Dispõe sobre a organização dos serviços de telecomunicações, a criação e funcionamento de um órgão regulador e outros aspectos institucionais, nos termos da Emenda Constitucional 8 de 1995, sendo conhecida como 'Lei Geral de Telecomunicações'. Disponível em: http://www.planalto.gov.br/ccivil_03/leis/19472.htm Acessado em: 28/06/2021.

BRASIL. Lei $n^{0}$ 9.610, de 19 de fevereiro de 1998. Altera, atualiza e consolida a legislação sobre direitos autorais e dá outras providências. Disponível em: http://www.planalto.gov.br/ccivil_03/leis/L9610.htm Acessado em 28/06/2021.

BRASIL. Lei $\mathbf{n}^{0}$. 9.615 de 24 de março de 1998 - Institui normas gerais sobre o desporto, tratando do direito de arena, sendo denominada como 'Lei Pelé'. Disponível em: http://www.planalto.gov.br/ccivil_03/leis/19615consol.htm Acessado em: 28/06/2021. 
DANTAS, Tiago. "Pirataria"; Brasil Escola. Disponível em:

https://brasilescola.uol.com.br/curiosidades/pirataria.htm. Acesso em 28 de junho de 2021.

GEERTZ, C. A Interpretação das Culturas. Rio de Janeiro: Guanabara, 1989.

GEERTZ, Clifford. From the Native's Point of View: On the Nature of Anthropological Understanding. Bulletin of the American Academy of Arts and Sciences, vol. 28, $\mathrm{n}^{\circ}$ 1, out. 1974.

HOBBES, Tomas. Leviatã ou matéria, forma e poder de um estado eclesiástico e civil. Tradução de João Paulo Monteiro e Maria Beatriz Nizza da Silva. São Paulo: Editora Nova Cultural, 1997 (Coleção Pensadores).

LOSSO, F.M. Os direitos autorais no Mercado da música. $253 \mathrm{f}$. Tese (Doutorado em Direito) - Faculdade de Direito, Universidade de São Paulo, São Paulo, 2008.

MARCIAL, Fernanda Magalhães. Os Direitos Autorais, sua proteção, a liberalidade na internet e o combate à pirataria. Âmbito Jurídico. Publicado em 01/04/2010. Disponível: https://ambitojuridico.com.br/edicoes/revista-75/os-direitos-autorais-sua-protecao-aliberalidade-na-internet-e-o-combate-a-pirataria/ Acessado em 28/06/2021.

MARQUES, Erickson Gavazza. Limites impostos pela legislação autoral aos cortes publicitários realizados durante a retransmissão de obras audiovisuais pela televisão. Revista da ABPI, nº 24, set./out. 1996.

PIMENTA, E.S. A função social dos direitos autorais da obra audiovisual. $156 \mathrm{f}$. Tese (Doutorado em Direito) - Departamento de Direito Civil, Universidade de São Paulo, São Paulo, 2008.

ROSENVALD, Nelson; FARIAS, Cristiano Chaves de. Direitos Reais. Rio de janeiro: Lumen Juris, 2007.

SHWEDER, Richard A. Preview: a colloquy of culture theorists. In: SHWEDER, Richard A. LEVINE, Robert. Culture theory: essays on mind, self and emotion. New York: Cambridge University Press, 1984. 
SILVA, José Afonso da. Ordenação constitucional da cultura. São Paulo: Malheiros, 2001.

STAUT JÚNIOR, S.S. Direitos Autorais entre as relações sociais e as relações jurídicas. Curitiba: Moinho do Verbo, 2006.

VAZ, Isabel. Direito econômico das propriedades. $1^{\text {a }}$ ed. Rio de Janeiro: Forense, 1992. 